\title{
Blood Pressure in Acute Stroke: Causes and Consequences
}

\author{
Bo Carlberg
}

\begin{abstract}
Patients with acute stroke often have high blood pressure levels the first days after hospital admission. The causes of high blood pressure in patients with acute stroke are incompletely known. In stroke patients with large cerebral lesions and impaired consciousness, high blood pressure seems to be secondary to high intracranial pressure and in these patients high blood pressure indicates a worse prognosis. In the majority of patients, alert on hospital admission, high blood pressure increases from hospitalization stress and is not related to a worse prognosis. (Hypertens Res 1994; 17 Suppl. I: S77-S82)
\end{abstract}

Key Words: antihypertensive drugs, blood pressure, cerebrovascular disorders

Patients with acute stroke often have high blood pressure levels the first days after hospital admission $(1,2)$. In an population-based study, $20 \%$ of all patients had an admission blood pressure of 220/115 $\mathrm{mmHg}$ or higher (3). These high blood pressure levels are the result of a blood pressure elevation compared with prestroke blood pressures (4), and in most patients, the blood pressure will normalize without treatment within a few days in hospital ( 1 , 3,5 ) (Fig. 1). The causes of high blood pressure in patients with acute stroke are incompletely known and the literature contains various recommendations regarding acute antihypertensive treatment to patients with acute stroke. This article will review possible mechanisms causing high blood pressure in patients with acute stroke and the prognostic value of high blood pressure in these patients.

\section{Why High Blood Pressure after Stroke?}

\section{Hypertension}

About $50 \%$ of all stroke patients have a previously known hypertension (1-3, 6-9). A history of hypertension affects the absolute blood pressure level in acute stroke, but the blood pressure course follows the same pattern in previously normotensive patients as in hypertensive patients $(3,5)$, Fig 1 .

\section{Cushing-Reflex}

High intracranial pressure may increase blood pressure through the Cushing-reflex (10). This wellknown mechanism is probably not of importance in the majority of stroke patients with small lesions. The vasogenic edema is maximal at the end of the first week after the stroke (11), but at that time the blood pressure is most often normalized.

\section{Homeostatic Response}

The elevated blood pressure has been proposed to be a beneficial homeostatic response aimed to increase blood flow in the ischemic penumbra (3). The mechanisms underlying this putative homeostatic response are not understood.

\section{Lesions in Cardiovascular Control Areas}

In experimental animals it is possible to increase or decrease blood pressure by stimulation or ablation in many regions of the nervous system, such as nucleus tractus solitarii in the medulla, the parabrachial nucleus of the pons, the hypothalamus, etc. (12, 13). In man, tumors at such locations have induced hypertension, and the hypertension has been cured after removal of the tumour (14). An autopsy study found patients with infarctions or hemorrhages in the pons to have had higher blood pressures before death than patients with lesions at other localisations (15). In a study including also survivors, patients with brainstem infarctions or TIA had no higher blood pressures than patients with cerebral hemispheric lesions(16). The importance of this type of blood pressure elevating mechanism in the total population of patients with acute stroke is unknown.

\section{Mental Stress}

The blood pressure course after stroke is more related to the time after hospitalization than to the time after onset of symptoms $(5,17)$. Patients with large neurological deficits do not have higher blood pressures than patients with small deficits or TIA (5). Therefore, mental stress at hospitalization has been proposed to be a significant blood pressure elevating factor in many patients with acute stroke. Hypertensive subjects without stroke have a blood pressure course after hospitalization that is similar 

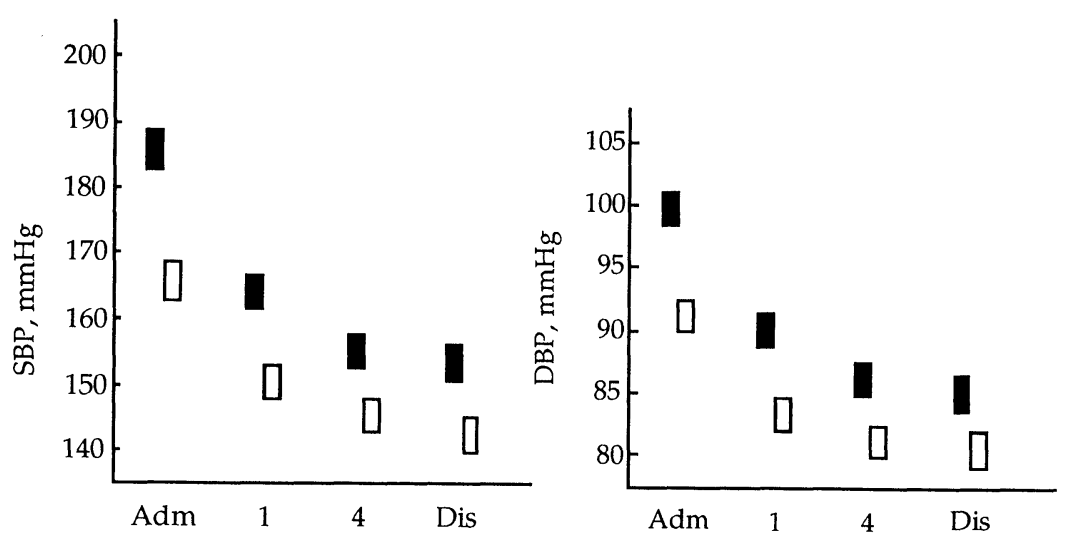

Fig. 1. Systolic $(S B P)$ and diastolic $(D B P)$ blood pressure course in stroke patients with previous hypertension ( $\mathbf{\square})$ and without previous hypertension ( $\square)$, at hospital admission $(A d m)$, the first day in the ward (1), the 4th day in the ward (4) and on discharge from hospital (Dis). The bars indicates $95 \%$ confidence intervals of the group mean values. From ref.5.

to the course in patients with acute stroke (18).

\section{Sympathetic Activation}

The blood pressure elevation in patients with acute stroke is thought to be mediated through sympathetic activation. Patients with acute stroke are hemodynamically characterised by an increased peripheral resistance (19). High catecholamine levels are found in plasma and urine during the first days or weeks after stroke (20). Catecholamine levels have been related to blood pressure levels in some $(21,22)$. but not in all studies $(23)$. Patients with impaired consciousness and high blood pressure refractory to antihypertensive treatment have very high catecholamine excretion (24). However, the secretion rate of norepinephrine and epinephrine seems to remain high for a longer period after stroke than blood pressure does (21, 22).

\section{Animal Studies}

It is difficult to reproduce a stroke in an elderly human in animal models. The use of anesthetics makes it difficult to study the "normal" blood pressure course after cerebral infarctions in animals. In many animal stroke models, blood pressure does not increase after middle cerebral artery occlusion (25-29) but this finding is not entirely consistent (30). There may also be different blood pressure responses after occlusion of the left compared to the right middle cerebral artery (31). The results from animal studies are probably not immediately transferable to stroke patients.

High blood pressure after stroke may thus have multiple etiologies. In patients with large cerebral lesions, especially intracerebral hemorrhages, the Cushing-reflex is the most important blood pressure-elevating mechanism. In patients with small lesions or TIA, hospitalization stress is probably the most important mechanism for the blood pressure course and the blood pressure level is dependent on the prestroke blood pressure level.

\section{Is High Blood Pressure Shortly after Stroke Associated with a Worse Outcome?}

A history of hypertension has been related to increased 30-day case fatality rate (32) and increased risk of stroke recurrence during the first 30 days after stroke (33). Other studies did not find a history of hypertension to result in a worse prognosis in the acute stage (34).

Studies on the association between initial blood pressure levels and short-term outcome in patients with acute stroke are summarized in Table 1. A majority of the studies found a worse prognosis in patients with high initial blood pressure levels. The relation between blood pressure levels and stroke prognosis is different in different subsets of stroke patients. Patients with impaired consciousness have a worse prognosis with higher blood pressure levels (40) (Fig. 2) probably reflecting high intracranial pressure. In alert patients, high blood pressure is not associated with worse outcome.

\section{Shall We Treat Hypertension in the Acute Phase of Stroke?}

The recommendations in the literature regarding treatment of high blood pressure in the acute phase of stroke are variable. Many advocate avoiding treatment (45-52), while others prefer to treat high blood pressures, e.g. $\geq 180 / 105 \mathrm{mmHg}(53-59)$. There are a number of concomitant disorders that definitely increase the need for acute treatment. Dissection of an aortic aneurysm where the dissection obstructs the flow to the brachiocephalic artery or the left common carotid artery is an unusual cause of stroke but necessitates acute antihypertensive therapy. The high blood pressure should be treated if overt heart failure, unstable angina or myocardial infarction is present. In patients with increased risk of hemorrhage from anticoagulant or thrombolytic therapy it may also be advantageous to lower high blood pressures. Other severe 
Table 1. Observational Studies Investigating the Association between Initial Blood Pressure Levels and Short-Term Outcome in Patients with Acute Stroke

\begin{tabular}{|c|c|c|c|c|c|}
\hline No. of pat. & Diagnosis & Endpoint & Blood pressure cut-off level & Results & Authors \\
\hline 92 & $\mathrm{I}+\mathrm{H}$ & mortality & $\begin{array}{l}\mathrm{SBP} \geq 220 \text { or } \\
\mathrm{DBP} \geq 120\end{array}$ & $-^{*}$ & Harmsen et al (35) \\
\hline 148 & $\mathbf{I}+\mathbf{H}$ & $\begin{array}{l}\text { ADL + } \\
\text { mortality }\end{array}$ & SBP & + & Allen (36) \\
\hline $6,395 ?$ & $\mathbf{I}+\mathbf{H}$ & mortality & $\begin{array}{l}\mathrm{SBP} \geq 200 \\
\mathrm{DBP} \geq 115\end{array}$ & $\begin{array}{l}-* \\
-*\end{array}$ & Hatano (37) \\
\hline 388 & $\mathrm{I}+\mathrm{H}$ & mortality & $\geq 220 / 115$ & - & Britton et al (38) \\
\hline 98 & I & deterioration & SBP & - & Dávalos et al (39) \\
\hline 1,273 & I & recurrence & $\begin{array}{l}\mathrm{SBP} \geq 160 \\
\mathrm{DBP} \geq 100\end{array}$ & $\begin{array}{l}= \\
-\end{array}$ & Sacco et al (33) \\
\hline 831 & I & mortality & MAP & $-10 \#$ & Carlberg et al (40) \\
\hline 94 & $\mathrm{H}$ & mortality & $\begin{array}{l}\text { SBP } \\
\mathrm{PP}>65\end{array}$ & $\begin{array}{l}= \\
-\end{array}$ & Turhim et al (41) \\
\hline 77 & $\mathrm{H}$ & mortality & n.p. & $=*$ & Dollberg et al (42) \\
\hline 85 & $\mathrm{H}$ & mortality & MAP & $-10 \#$ & Carlberg et al (40) \\
\hline 244 & $\mathrm{Hx}$ & mortality & n.p. & $={ }^{*}$ & Nath et al (43) \\
\hline 75 & $\mathrm{Hc}$ & deterioration & $\mathrm{SBP} \geq 200$ & - & Dunne et al (44) \\
\hline
\end{tabular}

$\mathrm{I}$, ischemic stroke; $\mathrm{H}$, hemorrhagic stroke; $\mathrm{Hx}$, the study also included cerebral hemorrhage of non-stroke origin; Hc, cerebellar hemorrhage; SBP, systolic blood pressure, $\mathrm{mmHg}$; DBP, diastolic blood pressure, mmHg; MAP, mean arterial blood pressure; PP, pulse pressure; n.p., not presented; + , better outcome with high blood pressure; -, worse outcome with high blood pressure; $=$, no association between outcome and blood pressure; $-/ 0$ \#, increased mortality in patients with impaired consciousness, but not in alert patients; ${ }^{*}$, statistics of the results not presented. Where no cut-off level is presented, blood pressure was used as a continuos variable.

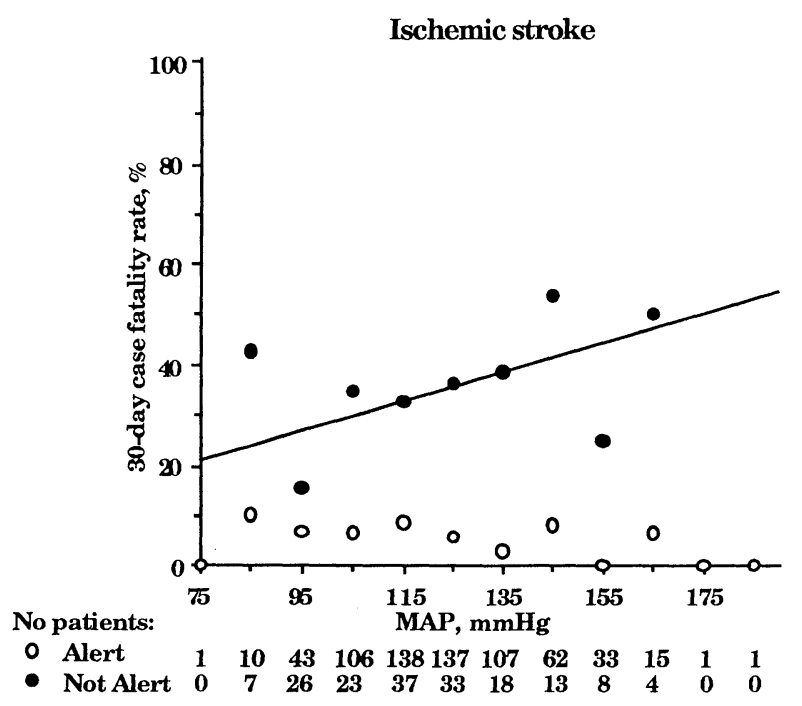

Fig. 2. Thirty-day case fatality rate in 831 stroke patients with different blood pressures at hospital admission. Filled circles, patients with impaired consciousness. Open circles, alert patients. The calculated regression lines for patients with impaired consciousness are inserted. From ref. 40.

hypertensive vessel disease, especially hypertensive encephalopathy, should also be treated.

In the more ordinary stroke patient, arguments for acute treatment are the edema around a hemorrhage or an infarction that may increase if blood pressure is high $(60)$. In experimental animals, a cerebral infarction may be transformed into a hemorrhagic infarction if the blood pressure is high (61). In stroke patients, hypertension may not involve a similar risk for hemorrhagic transformation (62).

On the other hand, in a patient with acute ischemic stroke, acute antihypertensive therapy may involve a substantial risk. The cerebral circulation may already be compromised by stenoses in the carotid arteries and other vessels. Autoregulation is impaired and therefore a blood pressure reduction may directly decrease blood flow in the already ischemic areas surrounding the infarct (63). Also, case reports in the literature describe patients who have deteriorated or died after acute blood pressure-lowering therapy $(46,64)$. Also, the spontaneous blood pressure decline after hospitalisation most often makes such therapy unnecessary. A study designed to evaluate the effect of acute antihypertensive therapy in patients with acute stroke and a diastolic blood pressure of $115-135 \mathrm{mmHg}$ was stopped because the spontaneous blood pressure fall during the $3 \mathrm{~h}$ of observation before randomisation was so common that only 18 out of 684 patients could be randomized (65). Acute antihypertensive therapy thus seems not to be indicated in most patients with acute ischemic stroke. The 
opposite, pharmacologically induced hypertension has been tested in patients with acute stroke. Some patients reacts with an immediate regression of symptoms, but the positive effect seems to be of short duration (66). In animal models, the beneficial effect of induced hypertension after experimental stroke $(67,68)$ is inconsistent with the deterioration after induced hypertension found in other studies (69). Induced hypertension may increase the cerebral edema and increase the risk for hemorrhage. Therefore, such therapy is probably not feasible in most patients with stroke (70).

The situation is somewhat different in patients with acute intracerebral hemorrhage. Intracerebral edema and high intracranial pressure are more pronounced than in cerebral infarctions. High blood pressure increase the edema (60), but the subsequent blood pressure elevation from the Cushingreflex helps to maintain cerebral perfusion pressure despite this high intracranial pressure. Rebleedings in the hematoma have been reported to occur mainly in patients with very high blood pressure (71, 72). The frequency of rebleedings is unknown and rebleedings diagnosed from clinical signs are very rare (71). With early and repeated CT-scans, rebleeding may be detected more commonly, especially among aspirin users (72).

On the other hand, the brain tissue around the hemorrhage may be hypoperfused if blood pressure is lowered and may result in infarction (46). In one study cerebral blood flow decreased if blood pressure was lowered more than 20\% (equal to prestroke levels in the study patients) in patients with acute intracerebral hemorrhage (73). With current information a cautious modest blood pressure reduction may be advantageous to prevent rebleeding and decrease the edema, but the total net gain of such therapy is unknown. It is difficult to perform and control such therapy in non-intensive stroke units.

\section{Treatment of High Blood Pressure in Patients with Acute Stroke}

If acute antihypertensive drug therapy has to be administered to a patient with acute stroke, the cerebrovascular effects of the drug must be taken in consideration.

Intracranial pressure may increase after acute administration of many antihypertensives. This has been shown with nifedipine (74), nitroglycerine (75), nitroprusside (76), dihyralazine (77), chlorpromazine (74) and reserpine (74).

Cerebral blood flow decreases after acute administration of diazoxide (78), clonidine (79) and betablockers $(80-81)$.

Diuretics (mainly furosemide for acute therapy) is preferable to patients with volume overload such as cardiac or renal failure. In other patients, diuretic therapy should be avoided as dehydration increase blood viscosity. Furosemide decreases elevated intracranial pressure (74) but the effect on blood pressure is usually small.

After acute administration of betablockers, cere- bral blood flow decreases and the acute effect on blood pressure is usually very modest. Combined alfa- and betablockers such as labetalol do not seem to have a similar deleterious effect on cerebral blood flow (78) and can be used if acute antihypertensive therapy is needed in stroke patients.

Calcium antagonists are widely used to patients with ischemic or hemorrhagic stroke. They may, however, increase intracranial pressure in patients with cerebral hemorrhage (74), and reduce cerebral blood flow in patients with cerebral infarction (63). Calcium antagonists should therefore be used with caution shortly after stroke.

ACE-inhibitors do not decrease cerebral blood flow (82). In patients with acute stroke, cerebral blood flow does not change after administration of captopril (83). ACE-inhibitors are therefore possible to use in patients with acute stroke. Low initial doses should be used to avoid hypertension in patients with activated renin-angiotensin system.

Central acting drugs like clonidine and alphamethyldopa should also be avoided because of the sedative effect.

If acute antihypertensive therapy is necessary in a patient with acute stroke, a combined alpha- and betablocker such as labetalol or ACE-inhibitors seems to be most advantageous. If the antihypertensive drug is given orally in low doses and after the first days in hospital, the acute effects on cerebral vessels are probably of less importance.

\section{References}

1. Wallace JD, Levy LL: Blood pressure after stroke. JAMA1981; 246: 2177-2180

2. Schulte BPM, Leyten ACM, Herman B: Pre-stroke and immediate post-stroke hypertension. neuroepidemiological data, in Meyer JS, Lehchner H, Reivick M, Ott E, (eds): Cerebral Vascular Disease (12th Salzburg Conference). Amsterdam, The Netherlands, Excerpta Medica, 1985; 286: 31-33.

3. Britton M, Carlsson A, De Faire U: Blood pressure course in patients with acute stroke and matched controls.Stroke 1986; 17: 861-864.

4. Kameyama M, Shio H, Akiguchi I, Fukuyama $H$ : Stroke and hypertension, in, Vinken PJ, Bruyn GW, Klawans HL, (eds): Handbook of Clinical Neurology. Vascular diseases part II. Amsterdam, The Netherlands, Elsevier, 1989; 54: 303-210.

5. Carlberg B, Asplund K, Hägg E: Course of blood pressure in different subsets of patients after acute stroke. J Cerebrovasc Dis 1991;1: 281-287.

6. Eriksson S, Asplund K, Hägg E, Lithner F, Strand T, Wester PO: Clinical profiles of cerebrovascular disorders in a population-based patient sample. $J$ Chronic Dis 1987;40: 1025-1032.

7. Bogousslavsky J, Van Melle G, Regli F: The Lansanne stroke registry: analysis of 1000 consecutive patients with first stroke. Stroke 1988;19: 1083-1092.

8. Mohr JP, Caplan LR, Melski JW, et al: The Harvard cooperative stroke registry: a prospective registry. Neurology 1978; 28: 754-762.

9. Foulkes MA, Wolf PA, Price TR, Mohr JP, Hier DB: The stroke data bank: design, methods, and baseline characteristics. Stroke 1988;19: 547-554.

10. Jones JV: Differentiation and investigation of primary versus secondary hypertension (Cushing reflex). Am J Cardiol 1989;63: 10C-13C. 
11. Silver FL, Norris JW, Lewis AJ, Hachinski VC: Early mortality following stroke: a prospective review. Stroke 1984; 15: 492-496.

12. Reis DJ: The brain and hypertension. Arch Neurol 1988; 45: 180-182.

13. Wyss JM, Oparil S, Chen Y-F: The role of the central nervous system in hypertension, in Laragh $\mathrm{JH}$, Brenner BM, (eds): Hypertension: Pathophysiology, Diagnosis and Management. New York, Raven Press Ltd., 1990. pp 679-701.

14. Bell GM. Intracranial disorders and hypertension in Laragh JH, Brenner BM (eds): Hypertension: Pathophysiology, Diagnosis and Management. New York, Raven Press Ltd., 1990, pp 703-709.

15. Ito A, Omae T, Katsuki S: Acute Changes in blood pressure following vascular diseases in the brain stem. Stroke 1973; 4: 80-84.

16. Marshall $\mathrm{J}$ : Evidence upon the neurogenic theory of hypertension. Lancet $1966 ; 1: 410-412$.

17. Carlberg B, Asplund K, Hägg E: Factors influencing admission blood pressure levels in acute stroke. Stroke 1991; 22: 527-530.

18. Hossman V, FitzGerald GA, Dollery CT: Influence of hospitalization and placebo therapy on blood pressure and sympathetic function in essential hypertension. Hypertension 1981; 3: 113-118.

19. Grotta JC, Pettigrew LC, Allen S, et al: Baseline hemodynamic state and response to hemodilution in patients with acute cerebral ischemia. Stroke 1985; 16: $790-795$.

20. Norris JW: Effects of cerebrovascular lesions on the heart. Neurol Clin 1983; 1: 87-101.

21. Meyer JS, Stoica E, Pascu I, Shimazu K, Hartmann A: Catecholamine concentrations in CSF and plasma of patients with cerebral infarction and haemorrhage. Brain 1973; 96: 277-288.

22. Jansen PAF, Thien T, Gribnau FWJ, et al: Blood pressure and both venous and urinary catecholamines after cerebral infarction. Clin Neurol Neurosurg 1988; 90: 41-45.

23. Myers MG, Norris JW, Hachinski VC, Sole MJ: Plasma norepinephrine in stroke. Stroke 1981; 12: 200-203.

24. Feibel JH, Baldwin CA, Joynt RJ: Catecholamineassociated refractory hypertension following acute intracranial hemorrhage: control with propranolol. Ann Neurol 1981; 9: 340-343.

25. Hachinski VC, Wilson JX, Smith KE, Cechetto DF: Effect of age on autonomic and cardiac responses in a rat stroke model. Arch Neurol 1992; 49: 690-696.

26. Slivka A: Age as a modifying factor on the effect antihypertensive therapy in focal stroke in rats. Stroke 1993; 24: 241-244.

27. Shima T, Hossman KA, Date H: Pial arterial pressure in cats following middle cerebral artery occlusion: 1. relationship to blood flow, regulation of blood flow and electrophysiological function. Stroke 1983; 14: 713-719.

28. Tamura A, Graham DI, McCulloch J, Teasdale GM: Focal cerebral ischemia in the rat: 1. description of technique and early neuropathological consequences following middle artery occlusion . J Cereb Blood Flow Metab 1981; 1: 53-60.

29. Tamura A, Graham DI, McCulloch J, Teasdale GM: Focal cerebral ischemia in the rat: 2 . regional cerebral blood flow determined by $\left[{ }^{14} \mathrm{C}\right]$ Iodoantipyrine autoradiography following middle cerebral artery occlusion. J Cereb Blood Flow Metab 1981; 1:61-69.

30. Cechetto DF, Wilson JX, Smith KE, Wolski D, Silver MD, Hachinski VC: Autonomic and myocardial changes in middle cerebral artery occlusion: stroke models in the rat. Brain Res 1989; 502: 296-305.

31 Hachinski VC, Oppenheimer SM, Wilson JX, Guiraudon C, Cechetto DF: Asymmetry of sympathetic consequences of experimental stroke. Arch Neurol 1992; 49: 697-702.

32. Rabkin SW, Mathewson FAL, Tate FB. The relation of blood pressure to stroke prognosis. Ann Intern Med 1978; 89: 15-20.

33. Sacco RL, Foulkes MA, Mohr JP, Wolf PA, Hier DB, Price TR: Determinants of early recurrence of cerebral infarction. The stroke date bank. Stroke 1989; 20: 983-989.

34. Chambers BR, Norris JW, Shurvell BL, Hachinski VC: Prognosis of acute stroke. Neurology 1987; 37: 221-225.

35. Harmsen P, Tibblin G: A stroke register in Göteborg, Sweden. Acta Med Scand 1972;191: 463-470.

36. Allen CMC: Predicting the outcome of acute stroke: a prognostic score. J Neurol Neurosurg Psychiatry 1984; 47: 475-480.

37. Hatano S: Experience from a multicentre stroke register: a preliminary report. Bull World Health Organ 1976; 54: 541-553.

38. Britton M, Carlsson A: Very high blood pressure in acute stroke. I Intern Med 1990; 228: 611-615.

39. Dávalos A, Cendra E, Teruel J, Martinez M, Genis D: Deteriorating ischemic stroke: risk factors and prognosis. Neurology 1990; 40: 1865-1869.

40. Carlberg B, Asplund K, Hägg E: The prognostic value of admission blood pressure in patients with acute stroke. Stroke 1993; 24: 1372-1375.

41. Tuhrim S, Dambrosia JM, Price TR, et al: Prediction of intracerebral hemorrhage survival. Ann Neurol 1988; 24: 258-263.

42. Dollberg S, Rosin AJ, Fisher D: A new look at the natural history and clinical features of intracerebral haemorrhage: a clinical CT scan correlation. Gerontology 1986;32: 211-216.

43. Nath FP, Nicholls D, Fraser RJA: Prognosis in intracerebral haemorrhage. Acta Neurochir (Wien) 1993; 67: 29-35.

44. Dunne JW, Chakera T, Kermode S: Cerebellar haemorrhage-diagnosis and treatment: a study of 75 consecutive cases. $Q J$ Med 1987;245: 739-754.

45. Jansen PAF, Schulte BPM, Poels EFJ, Gribnau FWJ: Course of blood pressure after cerebral infarction and transient ischemic attack. Clin Neurol Neurosurg 1987; 89: 243-246.

46. Lavin P: Management of hypertension in patients with acute stroke. Arch Intern Med 1986; 146: 66-68.

47. Wood DH: Managing the hypertensive patient with cerebrovascular disease. J Natl Med Assoc 1984; 76: 16-23.

48. Yatsu FM, Zivin J: Hypertension in acute ischemic strokes: not to treat. Arch Neurol 1985; 42: 999-1000

49. Hachinski V: Hypertension in acute ischemic strokes. Arch Neurol 1985; 42: 1002.

50. Britton M, Carlsson A: Very high blood pressure in acute stroke. J Intern Med 1990; 228: 611-615.

51. Shuaib A: Alterations of blood pressure regulation and cerebrovascular disorders in the elderly. Cerebrovasc Brain Metab Rev 1992; 4: 329-345.

52. Strandgaard S, Paulson OB: Pathophysiology of stroke. J Cardiovasc Pharmacol 1990; 15 (suppl 1): S38-S42.

53. Gottstein U, Seel AW: Antihypertensive therapy in stroke patients. Acta Neurol Scand 1977; 64: 174-177.

54. Breslin DJ, Swinton NW: Hypertension and cerebrovascular disease. Primary Care 1980; 7: 49-58. 
55. Spence JD: Hypertension in acute ischemic strokes. Treat. Arch Neurol 1985; 42: 1000-1002.

56. Brott T, MacCarthy EP: Antihypertensive therapy in stroke, in Fisher M, (ed): Medical Therapy of Acute Stroke. New York, Marcel Dekker Inc, 1989, pp117-141.

57. Anderson RJ: Current concepts in treatment of hypertensive urgencies. Am Heart $J$ 1986; 111: 211-219.

58. Gifford RW: Management of hypertensive crises. JAMA 1991; 266: 829-835.

59. Caplan LR: Intracerebral haemorrhage. Lancet 1992; 339: $656-658$.

60. Durward QJ, DelMaestro RF, Amacher AL, Farrar $\mathrm{JK}$ : The influence of systemic arterial pressure and intracranial pressure on the development of cerebral vasogenic edema. J Neurosurg 1983; 59: 803-809.

61. Saku Y, Choki J, Waki R, et al: Hemorrhagic infarct induced by arterial hypertension in cat following middle cerebral artery occlusion. Stroke 1990; 21: 589-595.

62. Oppenheimer S, Hachinski V: Complications of acute stroke. Lancet 1992; 339: 721-724.

63. Lisk DR, Grotta JC, Lamki LM, et al: Should hypertension be treated after acute stroke? a randomized controlled trial using single photon emission computed tomography. Arch Neurol 1993; 50: 855-862.

64. Britton M, de Faire U, Helmers C: Hazards of therapy for excessive hypertension in acute stroke. Acta Med Scand 1980; 207: 253-257.

65. Carlsson A: Management of high blood pressure in stroke patients. Stockholm, Karolinska Institute, 1993, Dissertation.

66. Meier F, Wessel G, Thiele R, Gottschild D, Brandstätt $\mathrm{H}$ : Induced hypertension as an approach to treating acute cerebrovascular ischemia: possibilities and limitations. Exp Pathol 1991; 42: 257-263.

67. Hayashi S, Nehls DG, Kieck CF, Vielma J, de Girolami U, Crowell RM: Beneficial effects of induced hypertension on experimental stroke in awake monkeys. J Neurosurg 1984; 60: 151-157.

68. Cole DJ, Matsumura JS, Drummond JC, Schell RM: Focal cerebral ischemia in rats: effects of induced hypertension, during reperfusion, on CBF. J Cereb Blood Flow Metab 1992; 12: 64-69.

69. Dutka AJ, Hallenbeck JM, Kochanek P: A brief episode of severe arterial hypertension induces delayed deterioration of brain function and worsens blood flow after transient multifocal cerebral ischemia. Stroke 1987; 18: 386-395.

70. Grotta JC: Can raising cerebral blood flow improve outcome after acute cerebral infarction? Stroke 1987;
18: $264-267$

71. Chen ST, Chen SD, Hsu CY, Hogan EL: Progression of hypertensive intracerebral hemorrhage. Neurology 1989; 39: 1509-1514.

72. Broderick JP, Brott TG, Tomsick T, Barsan W, Spilker J: Ultra-early evaluation of intracerebral hemorrhage. J Neurosurg 1990, 72: 195-199.

73. Kaneko $T$, Sawada $T$, Niimi $T$, Naritomi $H$, Kuriyama Y, Kinugawa $\mathrm{H}$ : Lower limit of blood pressure in treatment of acute hypertensive intracranial hemorrhage $(\mathrm{AHCH}) . J$ Cereb Blood Flow Metab 1983; 3 suppl 1: S51-S52.

74. Hayashi M, Kobayashi $\mathrm{H}$, Kawano H, Handa $\mathrm{Y}$, Hirose S: Treatment of systemic hypertension and intracranial hypertension in cases of brain hemorrhage. Stroke 1988; 19: 314-321.

75. Cottrel JE, Gupta B, Rappaport H, Turndorf, Ransohoff J, Flamm ES: Intraccranial pressure during nitroglycerin-induced hypertension. Neurosurg 1980; 53: 309-311.

76. Cottrel JE, Patel $\mathrm{K}$, Turndorf $\mathrm{H}$, Ransohoff $\mathrm{J}$ : intracranial pressure changes induced by sodium nitroprusside in patients with intracranial mass lesions. $J$ Neurosurg 1978; 48: 329-331.

77. Skinh $\varnothing \mathrm{j}$ E, Overgaard J: Effect of dihydralazine on intracranial pressure in patients with severe brain damage. Acta Med Scand 1983; 678 (suppl): 83-87.

78. Pearson RM, Griffith DNW, Woollard M, James IM, Havard CWH: Comparison of effects on cerebral blood flow of rapid reduction in systemic arterial pressure by diazoxide and labetalol in hypertensive patients: preliminary findings. $\mathrm{Br} \mathrm{J}$ Clin Pharmacol 1979; 8: 195S-198S.

79. Bertel O, Marx BE, Conen D: Effects of antihypertensive treatment on cerebral perfusion. $A m J$ Med 1987; 82 (suppl 3B): 29-36.

80. Hares P, James IM, Griffith D: The effect of acebutolol on the cerebral circulation of man. $\mathrm{Br} \mathrm{J}$ Clin Pharmacol 1977; 4: 373-375.

81. Meyer JS, Okamoto S, Sari A, et al: Effects of betaadrenergic blockade on cerebral autoregulation and chemical vasomotor control in patients with stroke. Stroke 1974; 5: 167-179.

82. Waldemar G, Schmidt JF, Andersen AR, Vorstrup $\mathrm{S}$, Ibsen H, Paulson OB: Angiotensin converting enzyme inhibition and cerebral blood flow autoregulation in normotensive and hypertensive man. $J$ Hypertens 1989; 7: 229-235

83. Waldemar G, Vorstrup S, Andersen AR, Pedersen $\mathrm{H}$, Paulson OB: Angiotensin-converting enzyme inhibition and regional cerebral blood flow in acute stroke. J Cardiovasc Pharmacol 1989; 14: 722-729. 